\title{
The psychiatry of children aged 0-4: advances in assessment, diagnosis and treatment ${ }^{\dagger}$
}

\author{
David Foreman
}

\begin{abstract}
SUMMARY
Mental illness in very young children is relatively rare and the number of 0 - to 4 -year-olds seen in secondary care psychiatric services has recently declined. Conceptualisation of mental illness in this age group is shifting towards a model that views disorders as part of the wider spectrum of diagnoses, rather than distinct, developmentally specific conditions. This article discusses the epidemiology of psychiatric illness in preschool children, evaluates assessment tools that have only recently been validated for use in secondary care and considers evidence of the efficacy and cost-effectiveness of early intervention using treatments encompassing pharmacological, psychological and social approaches.
\end{abstract}

\section{LEARNING OBJECTIVES}

- Understand the nature of psychiatric illnesses in preschool children, recognising that presentations may differ but the underlying conditions are similar to those observed in older age groups

- Appreciate the range and relative merits of diagnostic instruments available for identifying psychiatric disorders in this age group

- Recognise the effectiveness of various treatment modalities, especially public mental health and psychological approaches

\section{DECLARATION OF INTEREST}

None

Our understanding of the mental health of infancy and early childhood ( $0-4$ years of age) is undergoing a transformation. Traditional psychodynamic developmental accounts are transforming into operationalised, ethological accounts of cognitive processes and adult-child interaction. Intrauterine and early-life development are being increasingly implicated in the aetiology of both child and adult mental illness, while psychological trauma and adversity in this period are being associated with physical as well as mental ill health. The concept of developmentally specific psychiatric syndromes, which underpinned diagnosis for these children, is being eroded. In treatment, there has been increasing recognition of the economic advantages of early intervention, and primary care has engaged extensively with parent training, with good effect. However, in the UK secondary care capacity for 0- to 4-year-old children declined by $16.9 \%$ between 2006 and 2009, and an unpublished survey conducted by the Royal College of Psychiatrists in 2012 found that $28 \%$ of UK child psychiatrists believed that general child and adolescent mental health services (CAMHS) were not appropriate for the problems this group present. This article therefore gives an overview of the psychiatry of this age range, with the intention of improving awareness of the importance of mental health in children under 5, exploring the ways in which child psychiatrists may currently contribute, and indicating likely future directions for mental healthcare. A developmental psychopathology approach will be taken, to allow consideration of this group in terms of both current psychopathology and risk (and resilience) factors affecting later health difficulties.

\section{Diagnosis and epidemiology}

\section{Diagnosis}

The frequency of disorders in 0- to 4-year-olds cannot be determined without an agreed way to detect and classify them, and unfortunately diagnoses in this age range have been contentious. The traditional approach has been to emphasise differing developmental trajectories and adultchild (especially parent-child) relationships across broad behavioural domains, leading to differing forms of classification from those used in other population segments. In classic infant psychiatry, five domains were proposed as defining developmentally specific syndromes:

- pervasive developmental disorders

- reactive attachment disorders of infancy

- eating disorders of infancy

- sleep disorders

- disorders in behavioural organisation.
David Foreman was formerly Visiting Professor at Royal Holloway, University of London, and is currently co-opted to the Child and Adolescent and the Perinatal Faculties of the Royal College of Psychiatrists, as joint lead on children aged $0-4$. Correspondence Professor D. M Foreman, c/o BJPsych Advances, Publications Department, Royal College of Psychiatrists, 21 Prescot Street, London E1 8BB, UK. Email: david_foreman@doctors.net.uk

${ }^{\dagger}$ This is an updated version of a chapter published in Huline-Dickens S (ed) (2014) Clinical Topics in Child and Adolescent Psychiatry. RCPsych Publications. 
The first of these has now been extended into the category of autism spectrum disorders and is recognised as a lifespan diagnosis. Reactive attachment disorders have been shown to have a close developmental relationship with a range of similar behavioural, dissociative and affect-regulation problems in young adulthood, while eating and sleep problems also extend well outside infancy and so cannot be considered developmentally bound as originally thought. The last domain refers to temperamental problems sufficiently severe to trigger referral; once again, these now can be understood to refer to behavioural styles traceable from early childhood into adult life.

Findings such as these have undermined the validity of separate diagnostic classification systems for infants and young children, which were struggling to cope with poor reliability, especially with their proposed developmentally specific syndromes (Egger 2011). An interesting study used latent class analysis to compare diagnoses made under the best-developed developmentally specific diagnostic system, DC: 0-3R, with the two then current conventional systems, DSM-IV-TR and ICD-10: it found that the three systems identified similar latent classes, although the DSM and ICD coded them differently (Möricke 2013). This is also consistent with the extension of dimensional diagnostic approaches into the $0-4$ age range. Broad internalising and externalising dimensions have been found for the Child Behavior Checklist (CBCL) for ages 18 months to 5 years (Mothander 2008) and the Strengths and Difficulties Questionnaire (SDQ) for 2- to 3-year-olds (Delobel-Ayoub 2006), both of which have similar dimensional structures throughout their age ranges.

The evidence thus supports a conceptual shift from qualitatively distinct, developmentally specific syndromes to a developmentally modulated expression of psychopathological processes that are qualitatively similar across the lifespan. This carries implications for assessment, as the developmental differences between children of different ages then become primarily confounding factors in making accurate diagnoses, rather than markers for different groups of syndromes. This view does not exclude the idea that the onset of disorders may be developmentally related: this seems likely, for example, for depression and schizophrenia, although there is little evidence for such influences on remission. The shift described has led to practical progress, as assessment tools based on its assumptions have proved to have similar reliability to those already existing for older children, with a similar degree of syndrome resolution (Sterba 2007). It is therefore now both reasonable and possible to describe the epidemiology of psychiatric disorders in 0- to 4 -year-olds in terms of the disorders used across the rest of the age range.

\section{TABLE 1 Epidemiology of psychiatric disorders in preschool children}

\begin{tabular}{|c|c|c|c|c|}
\hline Study & Overall prevalence & Emotional diagnoses & Behavioural diagnoses & Comments \\
\hline Earls 1982 & $14 \%$ severe & $9 \%$ & $5 \%$ & Local sample of 100 children \\
\hline Lavigne 1996 & $21.6 \%$ probable, $9.1 \%$ severe & $\begin{array}{l}<1 \% \text { for any individual disorder } \\
\text { (CBCL identified } 3.7 \% \text { ) }\end{array}$ & $16.7 \%$ for ODD & $\begin{array}{l}\text { Two-stage sample }(3860 / 510) \\
\text { from primary care paediatricians }\end{array}$ \\
\hline Keenan 1997 & $26.4 \%$ (definite) & $14.9 \%$ (definite) & $14.9 \%$ (definite) & $\begin{array}{l}104 \text { low-income families from } \\
\text { support programme }\end{array}$ \\
\hline Egger 2006 & $16.2 \%$ & $10.5 \%$ & $9 \%$ & $\begin{array}{l}\text { Two-stage (1191/307) primary } \\
\text { care paediatric clinic sample }\end{array}$ \\
\hline Lavigne 2009 & Not given & $\begin{array}{l}0.6-2.1 \% \text { anxiety, depending } \\
\text { on assessment tool; }<1 \% \\
\text { depressive disorders }\end{array}$ & $\begin{array}{l}\text { 8.3\% ODD (severe); } 8.8 \% \\
\text { ADHD (severe) }\end{array}$ & $\begin{array}{l}\text { Single-stage (796) school and } \\
\text { paediatric clinic sample }\end{array}$ \\
\hline Bufferd 2011 & $\begin{array}{l}27.4 \% \\
(22.5 \% \text { without specific phobia) }\end{array}$ & $20.3 \%$ & $10.2 \%$ & $\begin{array}{l}\text { Area sample (541 interviewed, } \\
815 \text { eligible) }\end{array}$ \\
\hline Gleason 2011 & $8.8 \%$ & $5.4 \%$ & $1.4 \%$ & $\begin{array}{l}\text { Paediatric sample of } 1003 \\
\text { children assessed in a two- } \\
\text { stage, severity-stratified design }\end{array}$ \\
\hline Wichstrøm 2012 & $\begin{array}{l}12.1 \% \\
\text { (rate without encopresis } 7.1 \% \text { ) }\end{array}$ & $3.3 \%$ & $3.5 \%$ & $\begin{array}{l}\text { City-wide sample covering } \\
\text { all births over } 2 \text { years ( } 3456), \\
\text { severity-stratified sample of } 995 \\
\text { assessed }\end{array}$ \\
\hline Gudmundsson 2013 & $\begin{array}{l}10.1 \% \\
\text { (rate with encopresis and } \\
\text { enuresis 18\%) }\end{array}$ & $\begin{array}{l}5.7 \% \text { anxiety; depression } \\
\text { percentage not reported } \\
\text { (only } 1 \text { case was found) }\end{array}$ & $2.8 \%$ ODD; $3.8 \%$ ADHD & $\begin{array}{l}339 \text { sampled at routine check-up, } \\
\text { two-stage design, 4-6 age range }\end{array}$ \\
\hline
\end{tabular}

ADHD, attention-deficit hyperactivity disorder; CBCL, Child Behavior Checklist; ODD, oppositional defiant disorder. 


\section{Epidemiology}

One effect of these diagnostic concerns has been that, to date, there have been only nine prevalence studies of diagnosis of children aged 0-4. Table 1 summarises their findings.

Five studies were published since 2009, reflecting the epidemiological advantage of the newly changed paradigm. All the studies in Table 1 made use of versions of DSM as their diagnostic schema. It can be seen that the reported prevalence rates closely resemble the patterns found in older children: the range is similar, and the sensitivity to population and instrument choice suggested by the wide variations reported is also found more generally. It therefore seems likely that disorders present similarly, and with similar degrees of impairment, in children aged 0-4 as they do in older children and teenagers. The recent decline in UK CAMHS capacity for 0- to 4 -year-olds is therefore worrying, as it occurred during a period of increased investment and interest in CAMHS, and rising reported prevalence rates of child psychiatric disorders worldwide (Twenge 2011).

\section{Clinical assessment of 0- to 4-year-olds in secondary care}

In primary care, there are now well-established tools that may be used, or adapted, for the assessment of children with mental health problems, as fine-grained diagnosis is not usually required. However, in secondary care more diagnostic precision is needed, and we have already seen that adequately reliable and valid diagnostic systems have only recently been established for children aged $0-4$. In the UK, the lack of confidence this is likely to engender is combined with both low levels of service activity and limited training opportunities. The Royal College of Psychiatrists' survey found that $93 \%$ of non-specialist UK child psychiatrists saw not more than four 0 - to 4 -year-olds a month, and this was true even for $73 \%$ of those who reported working in a service that specialised in this age range; unsurprisingly, comments that they were inadequately trained to see this age group were common. These concerns were entirely justified under the paradigm of developmentally specific psychopathology, where assessments stress detailed interpretation of (possibly videotaped) parent-child interaction, and the use of instruments to assess individual differences in attachment and temperament that quantify risk and resilience factors, rather than assisting conventional diagnoses. However, the reformulation of early diagnosis described above suggests that child psychiatrists' existing skills, appropriately supported by diagnostically oriented structured assessment tools, will enable effective diagnosis in secondary care. Table 2 provides a list of instruments suitable for this. A discussion of issues of interpretation of structured instruments is provided in Szaniecki \& Barlow (2015). Although there is an overlap between preschool and autism assessment, the latter is not the focus here, and a comprehensive review of instruments for autism spectrum disorders is available elsewhere (Falkmer 2013).

Table 2 shows the wide range of valid and reliable assessment tools appropriate for children aged $0-4$ that are now available. The validation study of the Schedule for Affective Disorders and Schizophrenia for school-age children (Kiddie-), Present and Lifetime (K-SADS-PL) is especially encouraging, as it supports the view that existing adult instruments may be readily adapted for use in younger age ranges (Birmaher 2009), which follows from the claim that the psychiatric disorders to be identified are not developmentally bound syndromes. Clinicians thus can make detailed, standardised assessments, or use instruments to forewarn or support their clinical impressions and judgements. Either technique supports diagnostic accuracy. Although it measures a risk/resilience factor rather than providing a diagnosis, the Attachment Q-Sort is included in the table because attachment-related difficulties load on different dimensions from conventional psychopathology (Minnis 2007), and so could be missed without a specific measure. However, inspection of Table 2 shows that structured assessment is still challenging in children below 18 months of age. For example, although Szaniecki \& Barlow (2015) reported both the Ages \& Stages Questionnaires: Social Emotional (ASQ:SE) and the Brief Infant Toddler Social Emotional Assessment (BITSEA) as having promise, both of these questionnaires failed to distinguish psychopathology in children less than 24 months of age (de Wolff 2013).

\section{Child psychiatry and early intervention \\ Concepts of developmental psychobiology}

The first strand of the case for early intervention is, in some ways, a return to the roots of psychobiological child guidance as prevention of psychiatric disorders across the lifespan. There has been an increasing body of evidence consistent with developmental psychobiological concepts, such as psychobiological developmental pathways to physical and mental difficulties. For example, postnatal depression is associated with children's sleep difficulties, poor weight gain and increased minor physical problems at 9 months, impaired cognition at 16 months, impaired growth as well 


\begin{tabular}{|c|c|c|}
\hline Instrument & Description & Comments \\
\hline 3Di & $\begin{array}{l}\text { Computerised interview for the diagnosis of autism } \\
\text { together with likely confounders and comorbidities, } \\
\text { including wide diagnostic range in long form; provides ICD } \\
\text { diagnoses }\end{array}$ & $\begin{array}{l}\text { Flexible, semi-structured parental interview that also collects school information: } \\
\text { many items salient to infants or very young children; some items may also be used as } \\
\text { observation points with the child; has long and short form; only the autism diagnosis } \\
\text { has published validation }\end{array}$ \\
\hline ADI-R/ADOS & $\begin{array}{l}\text { Parental interview (ADI-R) and observation schedule } \\
\text { (ADOS) for diagnosis of autism }\end{array}$ & $\begin{array}{l}\text { Currently best-validated tool for autism diagnosis; covers much narrower range of } \\
\text { diagnoses than long version of 3Di; separate tools, designed to work together }\end{array}$ \\
\hline ASEBA & $\begin{array}{l}\text { Combination of questionnaires and semi-structured } \\
\text { interviews to obtain multi-informant, dimensional } \\
\text { assessments with population-based cut-offs }\end{array}$ & $\begin{array}{l}\text { An extension of the well-known CBCL to cover the whole lifespan from } 18 \text { months } \\
\text { onwards; though distinct, symptom profiles derived from its dimensions have been } \\
\text { mapped to common DSM diagnoses }\end{array}$ \\
\hline $\begin{array}{l}\text { Attachment } \\
\text { Q-Sort }\end{array}$ & $\begin{array}{l}\text { Set of cards with descriptors of infant ( } 1 \text { year and over) } \\
\text { behaviour, to be sorted by either observer or parent }\end{array}$ & $\begin{array}{l}\text { Best-validated alternative to Ainsworth's Strange Situation, which is not usually } \\
\text { appropriate in clinical setting; observer sorting has better validity than maternal } \\
\text { sorting; structuring the observational setting may be used to shorten observation time } \\
\text { (90min minimum); like the Strange Situation, does not diagnose attachment disorder }\end{array}$ \\
\hline $\begin{array}{l}\text { CHAT/ } \\
\text { M-CHATa }\end{array}$ & $\begin{array}{l}\text { Brief screening tool to detect autism from } 18 \text { months; } \\
\text { there are associated observer ratings (original CHAT), brief } \\
\text { telephone and observational structured interviews }\end{array}$ & $\begin{array}{l}\text { Significant level of false positives obtained from parent-only responses can be reduced } \\
\text { by using the additional associated assessments; is one of a number of alternative } \\
\text { screening tools available, but was designed to work with the youngest children in whom } \\
\text { symptoms could be meaningfully discriminated }\end{array}$ \\
\hline DAWBA & $\begin{array}{l}\text { Web-based combined structured and semi-structured } \\
\text { multi-informant interview for ICD and DSM diagnoses }\end{array}$ & $\begin{array}{l}\text { Validation on 2- to 4-year-olds complete but unpublished (report viewed by author); may } \\
\text { underdetect autism }\end{array}$ \\
\hline DISCO & $\begin{array}{l}\text { Comprehensive clinical assessment for autism spectrum } \\
\text { disorders and associated problems said to cover the full } \\
\text { age range }\end{array}$ & $\begin{array}{l}\text { Published validation from around 2-3 years onwards, across whole range of autism } \\
\text { spectrum; validation includes intellectual disability, may have advantages for this } \\
\text { group; collects data on wide range of symptoms, allows diagnosis of other psychiatric } \\
\text { disorders also }\end{array}$ \\
\hline $\mathrm{ECl}-4$ & $\begin{array}{l}\text { Parent- and teacher-completed rating scale for DSM-IV } \\
\text { diagnoses, optimised for age } 3-6 \text { years }\end{array}$ & $\begin{array}{l}\text { Items closely matched to DSM-IV criteria, has good convergent validity with other } \\
\text { instruments }\end{array}$ \\
\hline K-SADS-PL & $\begin{array}{l}\text { Semi-structured interview and examination developed for } \\
\text { school-age children; provides DSM-IV diagnoses }\end{array}$ & Has more items dealing with psychotic phenomena than either 3Di or DAWBA \\
\hline NBAS & $\begin{array}{l}\text { Observer-rated scale covering both neurological and } \\
\text { behavioural domains of neonatal assessment from birth to } \\
2 \text { months; the scale is to produce a profile, rather than be } \\
\text { summative }\end{array}$ & $\begin{array}{l}\text { Although designed as a scale, in clinical use it is recommended both to structure clinical } \\
\text { assessment and feed back recommendations to parents on how to respond to baby; has } \\
\text { predictive validity, but construct validity and reliability hard to interpret given variability } \\
\text { in neonates }\end{array}$ \\
\hline PAPA & $\begin{array}{l}\text { Standardised psychiatric assessment providing DSM-IV } \\
\text { diagnoses }\end{array}$ & $\begin{array}{l}\text { Probably the most extensively validated general diagnostic instrument for DSM } \\
\text { diagnoses }\end{array}$ \\
\hline PAS-R & 30 -item checklist for parents of children aged $3-5$ years & $\begin{array}{l}\text { No obsessive-compulsive items (owing to problems in measurement in this age range), } \\
\text { but best-validated scale for preschool anxiety available }\end{array}$ \\
\hline PFC & $\begin{array}{l}\text { Brief parent-report checklist for identification of depression } \\
\text { in 3- to 5-year-old children }\end{array}$ & The only depression-specific questionnaire of its type \\
\hline SDO & $\begin{array}{l}\text { Multi-informant screening questionnaire for emotional, } \\
\text { behavioural and hyperkinetic disorders and burden from } 3 \\
\text { years upwards }\end{array}$ & Web-based scoring system available; also incorporated as part of the DAWBA \\
\hline ABDD & $\begin{array}{l}\text { Structured, scored interpretation of clinician attempts to } \\
\text { interact with children aged } 2-24 \text { months }\end{array}$ & $\begin{array}{l}\text { Clinical cut-off has been replicated internationally; has } 2 \text { dimensions (temperamental } \\
\text { and interpersonal) and is predictive of relationship and behavioural problems at } 3 \text { and } 5 \\
\text { years respectively }\end{array}$ \\
\hline
\end{tabular}

a. The M-CHAT was preferred to the Social Communication Questionnaire (SCO) as there was evidence that the latter works less well in younger age ranges, requiring cut-off adjustment (Wiggins 2007). 3Di, Developmental, Dimensional and Diagnostic Interview; ADBB, Alarm Distress Baby scale; ADI-R, Autism Diagnostic Interview - Revised; ADOS, Autism Diagnostic Observation Schedule; ASEBA, Achenbach System of Empirically Based Assessment; Attachment Q-Sort; CHAT/M-CHAT, (Modified) Checklist for Autism in Toddlers; DAWBA, Development and Well-Being Assessment; DISCO, Diagnostic Interview for Social and Communication Disorders; ECI-4, Early Childhood Inventory for DSM-IV diagnoses; K-SADS-PL, Schedule for Affective Disorders and Schizophrenia for school-age children (Kiddie-), Present and Lifetime; NBAS, Neonatal Behavioral Assessment Scale; PAPA, Preschool Age Psychiatric Assessment; PAS-R, Preschool Anxiety Scale - Revised; PFC, Preschool Feelings Checklist; SDQ, Strengths and Difficulties Questionnaire.

as behavioural problems at age 2, and increased negative parenting behaviours, which persist, predicting increased behavioural and emotional problems by age 7 . Extreme prematurity, a physical perinatal stressor, is associated with subsequent impaired cognition (including executive function) and attention and internalising (though not externalising) behavioural problems (AarnoudseMoens 2009). However, there is little impact on family functioning in the long term, despite some restriction in opportunities for mothers, even in the presence of enduring neurodisability (Saigal 2010). Environmental toxins and recreational drugs are increasingly found to adversely affect the developing fetus, contributing to the risk for subsequent mental health problems. Recreational drugs are more associated with attentional problems, whereas environmental 
toxins have a general effect on brain development. Early chronic psychosocial trauma, stress and economic disadvantage have also been associated with subsequent neoplastic, gastrointestinal, cardiovascular and immunological illness, possibly via long-term immunological activation of macrophages or monocytes and subsequent hypersensitivity (Ford 2010; Miller 2011).

Among disorders more apparent in teenagers and adults, vulnerability to depression has been associated with the interaction between serotonin transporter gene polymorphisms and early psychological trauma, possibly mediated by impaired coupling between the amygdala and anterior cingulate cortex, as well as such trauma leading to hypothalamic-pituitary-adrenal (HPA) axis and oestrogenic dysregulation; the former is associated with impaired stress management, the latter potentially affects caregiving in subsequent generations. Chronic stress affects both the HPA axis and brain-derived neurotrophic factor (BDNF), leading to reduced hippocampal size and neuronal complexity, especially in the periventricular nuclei (Ansorge 2007). Our understanding of schizophrenia is also now neurodevelopmental, with obstetric complications and childhood or adolescent psychosocial stress both contributing to its eventual expression in genetically vulnerable people. Obstetric complications, in particular hypoxia, lead to more severe illness with earlier onset, and a greater likelihood for conversion of prodromal symptoms to the full syndrome. They have also been associated with ventricular enlargement (crucial evidence for the 'overpruning hypothesis' of excessive brain apoptosis in schizophrenia) and unusual movements at age 4, which both predicted incidence of schizophrenia. Brain-derived neurotrophic factor is implicated here as well: among individuals who begin life with obstetric complications, those who develop schizophrenia have lower than normal levels of this neuroprotective hormone, rather than the higher than normal levels in those who do not (Karlsgodt 2012). Early trauma also mediates this effect, possibly via inflammatory processes (Dennison 2012).

Developmental psychopathology has thus proved to be essential to our understanding of the major disorders treated in adult psychiatry, as well as those most prevalent in childhood and adolescence, and it highlights many potential areas for early intervention. The overall picture seems to be that similar stressors and risk factors (physical and psychological trauma and adversity early in life) produce a range of adverse results, the profile of which depends on the interaction between the insult and the individual's genotype, with families being more resilient to the sequelae of physical stressors than psychological or economic ones.

\section{The economic argument}

In the second strand of research supporting early intervention, Heckman (2008) developed an economic model based on developmental psychopathological findings, which suggested that the benefits across the lifespan of the ratio of early to later intervention in childhood followed a positive curvilinear relationship, i.e. early intervention was disproportionally beneficial compared with later. Data collection problems make this model difficult to test, but Knapp and colleagues have undertaken long-term (6-year) economic reviews of 15 early intervention strategies, with supportive results (Knapp 2011). For example, they found that early intervention for conduct disorder (which typically has a childhood onset) had a $20 \%$ greater return on investment than early detection of psychosis (which typically begins in adolescence), but even early intervention for conduct disorder has only $10 \%$ of the return on investment from prevention of conduct disorder through social and emotional learning programmes. Although these latter were evaluated in school, at 10 years, around $74 \%$ of conduct disorders are likely to have begun before then (Meltzer 2000) and social education programmes may be successfully adapted for preschool children. It therefore seems likely that the economic benefits of social and emotional learning programmes will be greater if used with preschool children. An interesting example is postnatal depression. Knapp et al's (2011) review, which did not consider children, failed to identify any return on investment in the deployment of health visitors. However, other studies obtained more positive results (McDaid 2011) and Knapp et al's most recent study (Bauer 2014) found that $72 \%$ of the costs of perinatal depression, anxiety and psychosis arose from the impact on the children, in which context interventions became highly cost-effective.

\section{The public mental health imperative}

The third strand supporting early intervention refers to cross-sectional, rather than longitudinal, findings. For adult and child health problems, the mean population score is closely related to the number of individuals with extreme values, i.e. the prevalence of relevant cases in the population (Goodman 2011). Therefore, whole-population interventions that reduce mean scores will also reduce associated case prevalences, so effective interventions may offer significant benefit in 
reducing case-load even if applied to at-risk or whole populations, rather than restricting them to diagnosed patients. From the last paragraph of the previous section, it follows that smaller, or even absent cross-sectional effect sizes may be accepted if the intent of an intervention is to reduce disability across the lifespan, given the potential offset in costs. An example where these principles could be applied is in preschool social education (Hamre 2012). Although prosocial behaviour in the preschoolers studied was significantly improved, there was no detectable change in the rate of behavioural disorders. However, this was because the base rate was so low in the study population that such change was hard to detect. The results suggested that the intervention would still be valuable in reducing the risk of future behavioural disorders, given their close negative association with prosocial behaviour.

A case can thus be made for child psychiatrists to involve themselves with 0 - to 4 -year-olds at the population level, as well as treating individual children, i.e. to engage with the public mental health of this age range. External observers consider that the UK (with The Netherlands) already leads the USA in this, and some of this work is undertaken as consultation-liaison to primary care teams and agencies (Embry 2011). In the UK, such teams can provide, jointly, around one potential worker for every 30 children with a diagnosable psychiatric disorder, and there is an appetite for appropriate training supported by management. In the USA, home-based treatment by such professionals has been shown to be feasible and effective for preschoolers (Lowell 2011) and, in general, interventions in this age group produce enduring benefit, which may be enhanced for mental health problems if provided in toddlerhood (Nores 2010). Despite this, and the theoretical account given above, a recent meta-analytic review found no prevention studies for depression covering the preschool age range (Merry 2012), though a randomised controlled trial for prevention of anxiety disorders in preschoolers is in progress (Bayer 2011).

\section{Treatment}

\section{Physical treatments}

Neuromodulation

Although these most frequently refer to psychopharmacology, it is important to remember that other physical treatments may be worthy of research in this age group. Electroconvulsive therapy (ECT) has been used for children, but not preschoolers, and its more acceptable - though possibly less effective - cousin transcranial magnetic stimulation (TMS) has also been trialled with adolescents for depression, with good results (Walter 2010). Conversely, vagus nerve stimulation (VNS) has been used extensively with children from less than 2 years of age to 18 for the treatment of epilepsy, and its antidepressant effect has been noted as well as its cognitive benefits (Klinkenberg 2013). Given our improved capacity for detecting mood disorders in this age group, and the currently worrying risk-benefit profile for antidepressants in juveniles, research is needed into applicable alternatives to medication. For example, TMS does not require general anaesthetic, does not require administration for months or years, is effective and has fewer sideeffects than antidepressants, although it can cause transient discomfort, particularly in its repetitive form.

\section{Exercise and neurofeedback}

Less controversially, exercise therapy is beneficial for children, including preschoolers, with intellectual disabilities and possibly for attentiondeficit hyperactivity disorder (ADHD) across the ability range (Berwid 2012). However, there have been no trials of exercise therapy for either ADHD in preschoolers without developmental delays, or for emotional disorders in any ability range, despite promising studies showing attenuating depression and anxiety in adults. There also continues to be no evidence - despite claims to the contrary - for the successful use of coordination training such as the Dore programme to treat ADHD, dyslexia or Asperger syndrome (Bishop 2007). Although developed by psychologists, biofeedback is a physical treatment, as it focuses on direct modification of aspects of physical function rather than behaviour. Biofeedback of electroencephalographic recordings (sometimes called neurofeedback) probably improves symptoms of ADHD (Lofthouse 2012), but its effect on autism is less clear. However, all studies have been on school-aged children or adults.

Clearly, some of these physical treatments are highly invasive, and should be reserved for very rare and severe cases. However, there appears to have been insufficient research conducted in preschool children even for physical treatments such as exercise or neurofeedback.

\section{Psychotropic medication}

In the 1990s, prescribing rates for psychotropic medication in preschoolers in the USA were reported at between 3 and 9 per 1000, possibly inflated by some prescriptions for parents not 
covered by Medicaid, and most prescriptions were for stimulants. A randomised controlled trial found that, while efficacious, stimulant medication in this group showed smaller effect sizes than in older children, a different side-effect profile and a greater withdrawal rate (Wigal 2006): the researchers recommended a 'start low and go slow' policy in this age group. A later US review identified prescriptions of antipsychotics to privately insured preschoolers rising from 0.78 per 1000 in $1999-2000$ to 1.54 per 1000 in 2007, with less than half receiving psychological treatment, a mental health assessment or a visit from a psychiatrist (Olfson 2010). The associated diagnoses were either ADHD or disruptive behaviour disorders: durations of treatment were lengthy and polypharmacy common. Introduction of a pre-approval system reduced the rate of requests, but a higher proportion of those continuing to submit were not child psychiatrists (Constantine 2012). Antipsychotics have only weak efficacy for ADHD and the core symptoms of autistic disorders, but carry similarly significant metabolic and neurological risks in this age range. Second-generation antipsychotics are effective for disruptive behaviour disorders, but in this age range parenting programmes are also effective, as discussed in the next section, and have better sideeffect profiles. There is little information available on medication for emotional disorders in 0 - to 4-year-olds.

Thus, although some children aged 0-4 may benefit from psychopharmacology, and drugs effective in older children are effective in this age range also, the evidence suggests that its use in such young children carries a less favourable balance of benefits and harms than in older children, as well as having less supporting evidence, and so more caution is advised.

\section{Psychological and social treatments}

The treatment of ADHD illustrates how approaches for older children might have to be modified for those of preschool age. It is frequently forgotten that, even for school-age children, welldesigned psychological treatments for ADHD have an effect, albeit less than medication, and with little evidence of additive benefit. With preschool children, the picture is different. Greenhill et al (2006) report an effect size for methylphenidate of 0.55 (probability of replication: 0.95 ) following behavioural treatment. The Incredible Years parenting programme has been reported to have an effect size of 0.73 (probability of replication: 0.96) for immediate effect on ADHD symptoms, which was maintained at 18-month follow-up
(Jones 2008). A parenting intervention specifically designed to target ADHD symptoms achieved an effect size of 0.79 (probability of replication: 0.99), maintained at 15 weeks. However, the programme could not be implemented effectively by newly trained staff outside the envelope of specialist care (Sonuga-Barke 2004). The success of this approach using specialist delivery may have been replicated (Thompson 2009), although the very high effect sizes reported could reflect the combination of a high drop-out rate and failure to analyse using intention to treat. However, a meta-analysis (Sonuga-Barke 2013) conducted to remove 'founder effects' (i.e. bias associated with assessments by the developer of the intervention) found that, overall, psychological treatment had no significant effect on the core ADHD symptoms (overactivity, impulsivity and inattention). This same meta-analysis confirmed modest effect sizes for the benefit of free fatty acid supplementation and artificial food colour exclusion, suggesting their utility in a public mental health, though not clinical, context.

High levels of heterogeneity between studies and variable study quality have also characterised early interventions for autism, although effect sizes at least as large as for drug treatment have been reported, and some trends are evident. Guidelines based on a systematic review of studies reporting outcomes in the preschool period concluded that children with autism spectrum disorders require a minimum of $25 \mathrm{~h}$ a week of behaviourally focused programmes, possibly including a developmental component (Maglione 2012). Not only does there seem to be a dose-response relationship between time taken and effectiveness, but a large welldesigned study in preschoolers using a focused parent-training approach achieved only small effect sizes on an intervention lasting $6.5 \mathrm{~h}$ a week ( $2.5 \mathrm{~h}$ of which were dedicated to unsupported homework) (Green 2010). Despite the large initial outlay required, the return on investment for such intensive treatments, estimated by cost-offset modelling and assuming intervention at 3 years of age, is around 11 to 1 (Peters-Scheffer 2012) by 65 years, consistent with Heckman's model discussed above, and is equivalent to an annualised return of about $16 \%$. It seems unlikely that treatments of the intensity and specificity required could be delivered outside specialist settings.

The implication of the admittedly sparse literature is that psychological treatment of preschoolers with significant autistic symptoms is to be preferred to drug treatment where possible, and is best delivered from specialist centres rather than in primary care. For ADHD, the failure to 
demonstrate the impact of psychological treatment on its core symptoms should not undermine decisions to prescribe it for associated comorbidity and disability, where indicated. However, it seems likely that this will require significant reconfiguration of current secondary care services. In the UK at present it takes, on average, 500 days for a referral for ADHD to lead to treatment, which is clearly far too long for a preschool intervention, while the implementation of intensive treatment for autism will require quite different resourcing from that offered by the typical current CAMHS team (Foreman 2010). Resolving these issues will require skilled clinical leadership.

\section{Conclusions}

Understanding of psychiatric diagnosis, epidemiology and treatment options for children aged 0-4 has changed greatly in the past 10 years, and the current disengagement that UK child psychiatry has with this age range is no longer warranted. Conventional diagnostic systems are appropriate for this age range, provided it is understood that development may affect symptom expression, whereas convincing evidence for developmentally specific syndromes is lacking. This has allowed the development of instruments which demonstrate that the epidemiology of psychiatric disorders in 0 - to 4-year-olds includes similar types and rates of disorder as in older children, with comparable disability. Two strands for intervention seem to hold particular promise for the future: engaging with the public mental health of this age range for both primary and secondary prevention; and psychological treatment of preschool autism and ADHD in secondary care. Both offer cost-effective treatment and prevention opportunities, but will require changes in service configuration, including appropriate child psychiatric engagement.

Public mental health is a newly emerging concept, but for young children, the Integrated Management of Childhood Illness (IMCI) strategy has proved effective and affordable in countries much poorer than the UK (Rakha 2013). Developed by the World Health Organization and UNICEF, IMCI targets a relatively small number of common illnesses with high morbidity and mortality by using simple, specific detection tools and treatments administered by primary care personnel. As this article has shown, similar tools and interventions are now available for the small number of conditions contributing to the burden of mental disorder in this age group, so the IMCI approach, which would situate appropriately trained and experienced child psychiatrists working in a teaching and consultative role with dedicated primary care staff, could well offer considerable dividends.

There is now also good understanding of psychological treatments for preschool children in secondary care; the major difficulties are establishing appropriate infrastructure to ensure sustained, high-quality delivery. Although the benefits of such interventions seem clear, there have been no studies of the economics driving the decisions that enable or disable infrastructure in this field, and disinvestment is currently occurring despite the opposing weight of academic and political opinion. Interdisciplinary research involving child psychiatrists, academic managers and health economists is likely to be needed if such services are to be successfully established.

\section{References}

Aarnoudse-Moens CSH, Weisglas-Kuperus N, van Goudoever JB, et al (2009) Meta-analysis of neurobehavioral outcomes in very preterm and/ or very low birth weight children. Pediatrics, 124: 717-28.

Ansorge MS, Hen R, Gingrich JA (2007) Neurodevelopmental origins of depressive disorders. Current Opinion in Pharmacology, 7: 8-17.

Bauer A, Parsonage M, Knapp M, et al (2014) Costs of Perinatal Mental Health Problems. LSE and Centre for Mental Health Research.

Bayer JK, Rapee RM, Hiscock H, et al (2011) The Cool Little Kids randomised controlled trial: population-level early prevention for anxiety disorders. BMC Public Health, 11: 11

Berwid OG, Halperin JM (2012) Emerging support for a role of exercise in attention-deficit/hyperactivity disorder intervention planning. Current Psychiatry Reports, 14: 543-51.

Birmaher B, Ehmann M, Axelson DA, et al (2009) Schedule for affective disorders and schizophrenia for school-age children (K-SADS-PL) for the assessment of preschool children: a preliminary psychometric study. Journal of Psychiatric Research, 43: 680-6.

Bishop DV (2007) Curing dyslexia and attention-deficit hyperactivity disorder by training motor co-ordination: miracle or myth? Journal of Paediatrics and Child Health, 43: 653-5.

Bufferd SJ, Dougherty LR, Carlson GA, et al (2011) Parent-reported mental health in preschoolers: findings using a diagnostic interview. Comprehensive Psychiatry, 52: 359-69.

Constantine R, Bengtson MA, Murphy T, et al (2012) Impact of the Florida Medicaid Prior-Authorization Program on use of antipsychotics by children under age six. Psychiatric Services, 63: 1257-60.

Delobel-Ayoub M, Kaminski M, Marret S, et al (2006) Behavioral outcome at 3 years of age in very preterm infants: the EPIPAGE study. Pediatrics, 117: 1996-2005.

Dennison U, McKernan D, Cryan J, et al (2012) Schizophrenia patients with a history of childhood trauma have a pro-inflammatory phenotype. Psychological Medicine, 42: 1865-71.

de Wolff MS, Theunissen MH, Vogels AG, et al (2013) Three questionnaires to detect psychosocial problems in toddlers: a comparison of the BITSEA, ASQ:SE, and KIPPPI. Academic Pediatrics, 13: 587-92.

Earls F (1982) Application of DSM-III in an epidemiological study of preschool children. American Journal of Psychiatry, 139: 242-3.

Egger HL, Erkanli A, Keeler G, et al (2006) Test-retest reliability of the Preschool Age Psychiatric Assessment (PAPA). Journal of the American Academy of Child \& Adolescent Psychiatry, 45: 538-49.

Egger HL, Emde RN (2011) Developmentally sensitive diagnostic criteria for mental health disorders in early childhood: the Diagnostic and Statistical Manual of Mental Disorders-IV, the Research Diagnostic 
Criteria-Preschool Age, and the Diagnostic Classification of Mental Health and Developmental Disorders of Infancy and Early ChildhoodRevised. American Psychologist, 66: 95-106.

Embry DD (2011) Behavioral vaccines and evidence-based kernels: nonpharmaceutical approaches for the prevention of mental, emotional and behavioral disorders. Psychiatric Clinics of North America, 34: $1-34$

Falkmer T, Anderson K, Falkmer M, et al (2013) Diagnostic procedures in autism spectrum disorders: a systematic literature review. European Child \& Adolescent Psychiatry, 22: 329-40.

Ford JD (2010) Complex adult sequelae of early life exposure to psychological trauma. In The Impact of Early Life Trauma on Health and Disease: The Hidden Epidemic (eds RA Lanius, E Vermetten, C Pain): 69-76. Cambridge University Press.

Foreman DM (2010) The impact of governmental guidance on the time taken to receive a prescription for medication for ADHD in England. Child and Adolescent Mental Health, 15: 12-7.

Gleason MM, Zamfirescu A, Egger HL, et al (2011) Epidemiology of psychiatric disorders in very young children in a Romanian pediatric setting. European Child \& Adolescent Psychiatry, 20: 527-35

Goodman A, Goodman R (2011) Population mean scores predict child mental disorder rates: validating SDQ prevalence estimators in Britain. Journal of Child Psychology and Psychiatry, 52: 100-8.

Green J, Charman T, McConachie H, et al (2010) Parent-mediated communication-focused treatment in children with autism (PACT): a randomised controlled trial. Lancet, 375: 2152-60.

Greenhill L, Kollins S, Abikoff $H$, et al (2006) Efficacy and safety of immediate-release methylphenidate treatment for preschoolers with ADHD. Journal of the American Academy of Child \& Adolescent Psychiatry, 45: 1284-93.

Gudmundsson 00, Magnusson P, Saemundsen E, et al (2013) Psychiatric disorders in an urban sample of preschool children. Child and Adolescent Mental Health, 18: 210-7.

Hamre BK, Pianta RC, Mashburn AJ, et al (2012) Promoting young children's social competence through the preschool PATHS curriculum and MyTeachingPartner professional development resources. Early Education and Development, 23: 809-32.

Heckman JJ (2008) Schools, skills, and synapses. Economic Inquiry, 46 : 289-324.

Jones K, Daley D, Hutchings J, et al (2008) Efficacy of the Incredible Years Programme as an early intervention for children with conduct problems and ADHD: long-term follow-up. Child: Care, Health and Development, 34: $380-90$.

Karlsgodt KH, Ellman LM, Sun D, et al (2012) The neurodevelopmental hypothesis of schizophrenia. In Schizophrenia: The Final Frontier. A Festschrift for Robin M. Murray (eds AS David, S Kapur, P McGuffin): 3-18. Psychology Press.

Keenan K, Shaw D, Walsh B, et al (1997) DSM-III-R disorders in preschool children from low-income families. Journal of the American Academy of Child \& Adolescent Psychiatry, 36: 620-7.

Klinkenberg S, van den Bosch CN, Majoie H, et al (2013) Behavioural and cognitive effects during vagus nerve stimulation in children with intractable epilepsy: a randomized controlled trial. European Journal of Paediatric Neurology, 17: 82-90.

Knapp M, McDaid D, Parsonage M (2011) Mental Health Promotion and Mental IIIness Prevention: The Economic Case. Department of Health.

Lavigne JV, Gibbons RD, Christoffel KK, et al (1996) Prevalence rates and correlates of psychiatric disorders among preschool children. Journal of the American Academy of Child \& Adolescent Psychiatry, 35: 204-14.

Lavigne JV, LeBailly SA, Hopkins J, et al (2009) The prevalence of ADHD, ODD, depression, and anxiety in a community sample of 4-year-olds. Journal of Clinical Child \& Adolescent Psychology, 38: 315-28.

Lofthouse N, Arnold LE, Hersch S, et al (2012) A review of neurofeedback treatment for pediatric ADHD. Journal of Attention Disorders, 16: 351-72.
Lowell DI, Carter AS, Godoy L, et al (2011) A randomized controlled trial of Child FIRST: a comprehensive home-based intervention translating research into early childhood practice. Child Development, 82: 193-208.

Maglione MA, Gans D, Das L, et al (2012) Nonmedical interventions for children with ASD: recommended guidelines and further research needs. Pediatrics, 130 (suppl 2): S169-78.

McDaid D, Park AL (2011) Investing in mental health and well-being: findings from the DataPrev project. Health Promotion International, 26 (suppl 1): i108-39

Meltzer H, Gatward R, Goodman R, et al (2000) Mental Health of Children and Adolescents in Great Britain. TSO (The Stationery Office).

Merry SN, Hetrick SE, Cox GR, et al (2012) Cochrane Review: Psychological and educational interventions for preventing depression in children and adolescents. Evidence-Based Child Health: A Cochrane Review Journal, 7: 1409-685.

Miller GE, Chen E, Parker KJ (2011) Psychological stress in childhood and susceptibility to the chronic diseases of aging: moving toward a model of behavioral and biological mechanisms. Psychological Bulletin, 137: 959-97.

Minnis H, Reekie J, Young D, et al (2007) Genetic, environmental and gender influences on attachment disorder behaviours. British Journal of Psychiatry, 190: 490-5.

Möricke E, Lappenschaar GAM, Swinkels SH, et al (2013) Latent class analysis reveals five homogeneous behavioural and developmental profiles in a large Dutch population sample of infants aged 14-15 months. European Child \& Adolescent Psychiatry, 22: 103-15.

Mothander PR, Grette Moe R (2008) Infant Mental Health assessment: the use of DC 0-3 in an outpatient child psychiatric clinic in Scandinavia. Scandinavian Journal of Psychology, 49: 259-67.

Nores M, Barnett WS (2010) Benefits of early childhood interventions across the world: (under) investing in the very young. Economics of Education Review, 29: 271-82.

Olfson M, Crystal S, Huang C, et al (2010) Trends in antipsychotic drug use by very young, privately insured children. Journal of the American Academy of Child \& Adolescent Psychiatry, 49: 13-23.

Peters-Scheffer N, Didden R, Korzilius H, et al (2012) Cost comparison of early intensive behavioral intervention and treatment as usual for children with autism spectrum disorder in the Netherlands. Research in Developmental Disabilities, 33: 1763-72.

Rakha MA, Abdelmoneim AM, Farhoud S, et al (2013) Does implementation of the $\mathrm{IMCl}$ strategy have an impact on child mortality? A retrospective analysis of routine data from Egypt. BMJ Open, 3 (1): doi 10.1136/bmjopen-2012-001852.

Saigal S, Pinelli J, Streiner DL, et al (2010) Impact of extreme prematurity on family functioning and maternal health 20 years later. Pediatrics, 126: e81-8.

Sonuga-Barke EJ, Thompson M, Daley D, et al (2004) Parent training for attention deficit/hyperactivity disorder: is it as effective when delivered as routine rather than as specialist care? British Journal of Clinical Psychology, 43: 449-57.

Sonuga-Barke EJ, Brandeis D, Cortese S, et al (2013) Nonpharmacological interventions for ADHD: systematic review and meta-analyses of randomized controlled trials of dietary and psychological treatments. American Journal of Psychiatry, 170: 275-89.

Sterba S, Egger HL, Angold A (2007) Diagnostic specificity and nonspecificity in the dimensions of preschool psychopathology. Journal of Child Psychology and Psychiatry, 48: 1005-13.

Szaniecki E, Barnes J (2015) Measurement issues: measures of infant mental health. Child and Adolescent Mental Health, 23 Apr: doi 10.1111/ camh.12105 [online ahead of print]

Thompson MJ, Laver-Bradbury C, Ayres M, et al (2009) A smallscale randomized controlled trial of the revised new forest parenting programme for preschoolers with attention deficit hyperactivity disorder. European Child \& Adolescent Psychiatry, 18: 605-16.

Twenge JM (2011) Generational differences in mental health: are children and adolescents suffering more, or less? American Journal of Orthopsychiatry, 81: 469-72.

\section{MCO answers \\ 1 c 2 e 3 c $4 d \quad 5 d$}


Walter G, Rey JM, Ghaziuddin N, et al (2010) Electroconvulsive therapy, transcranial magnetic stimulation, and vagus nerve stimulation. In Pediatric Psychopharmacology: Principles and Practice (2nd edn) (eds A Martin, L Scahill, CJ Kratochvil): 363-375. Oxford University Press.

Wichstrøm L, Berg-Nielsen TS, Angold A, et al (2012) Prevalence of psychiatric disorders in preschoolers. Journal of Child Psychology and Psychiatry, 53: 695-705.
Wigal T, Greenhill L, Chuang S, et al (2006) Safety and tolerability of methylphenidate in preschool children with ADHD. Journal of the American Academy of Child \& Adolescent Psychiatry, 45: 1294-303.

Wiggins LD, Bakeman R, Adamson LB, et al (2007) The utility of the social communication questionnaire in screening for autism in children referred for early intervention. Focus on Autism and Other Developmental Disabilities, 22: 33-8.

\section{MCQs}

Select the single best option for each question stem

1 In a 2012 survey, the proportion of UK child psychiatrists who felt that general CAMHS services are not appropriate for the needs of children under 5 was:
a $8 \%$
b $15 \%$
c $28 \%$
d $45 \%$
e $69 \%$

2 In the same survey, the proportion of nonspecialist child psychiatrists who reported seeing not more than four children under 5 each month was:
a $34 \%$
b $51 \%$
a 0.12
b 0.29

c $64 \%$

d $79 \%$

e $93 \%$.

3 Which of the following is an assessment tool that involves an observer or parent arranging a set of descriptors of infant behaviour?

a $3 \mathrm{Di}$

b DISCO

c Attachment Q-Sort

d K-SADS-PL

e PAS-R.

4 The immediate effect size on ADHD reported for the Incredible Years parenting programme was:

\section{c 0.56}

d 0.73

e 0.91 .

5 Peters-Scheffer et al reported a return on investment by age 65 for intensive psychological intervention at age 3 of:
a 2 to 1
b 4 to 1
c 6 to 1
d 11 to 1
e 20 to 1 